\title{
Disseminated peritoneal leiomyomatosis verified by caesarean section - a case report
}

\author{
Rajko Fureš $^{1}$, Tonči Visković ${ }^{1}$, Cvjetko Lež ${ }^{2}$, Bruno Grabušić ${ }^{1}$, Danijela Batas ${ }^{1}$, Mirela Čarapina ${ }^{2}$, \\ Zlatko Hrgovic ${ }^{3}$
}

1. Department of Obstetrics and Gynaecology, Zabok General Hospital, Croatia. 2. Department of Pathology and Cytology, Zabok General Hospital, Croatia. 3. Department of Gynaekology, University Hospital, Osijek, Croatia.

Correspondence: Zlatko Hrgovic. Address: Department of Gynaekology, University Hospital, Osijek, Croatia. E-mail: info@hrgovic.de

Received: April 3, 2014

Accepted: July 28, 2014

Online Published: September 10, 2014

DOI: $10.5430 / \mathrm{crcp} . \mathrm{v} 2 \mathrm{n} 1 \mathrm{p} 12$

URL: http://dx.doi.org/10.5430/crcp.v2n1p12

\section{Abstract}

In this report we present a case of disseminated peritoneal leiomyomatosis which was discovered during an elective Caesarean section. Leiomyomatosis peritonealis disseminata (DPL) is a rare but well-documented disorder mainly found in women of reproductive age. It is characterized by small nodules on the peritoneal surface, that imitate a malignant process, but demonstrate benign histological features. DPL is usually discovered accidentally during other procedures, such as laparoscopy, cesarean section, laparotomy, tubal ligation, etc. Etiology is uncertain but DPL seems to be a multifactorial disease with a genetic or hormonal component (high levels of estrogen and progesterone) which leads to metaplasia of peritoneal mesenchymal cells. There is evidence that the DPL is a result of a hormonal disorder. When DPL occurs during pregnancy or during the use of birth control pills, it may regress spontaneously after delivery or after stopping the birth control treatment. This case report of DPL shows a pregnant woman who has used birth control pills for three years between her first und second pregnancies.

\section{Key words}

Disseminated peritoneal leiomyomatosis, Pregnancy

\section{Introduction}

Disseminated peritoneal leiomyomatosis (DPL) was first described in 1952 (Wilson and Pale). Up to date approximately 150 cases have been described. DPL is presented in a form of small multiple tumors, composed of smooth muscle tissue, which are spread throughout the peritoneum. It is usually an accidental finding during surgery (cesarean section, laparoscopy, laparotomy). This benign disorder is often confused with peritoneal carcinomatosis, because their macroscopic appearances are very similar. In the majority of described cases, patients were in the reproductive period, and most of them were pregnant. Those who were not pregnant took oral contraceptives ${ }^{[1,2]}$.

\section{Case report}

In this paper we present a case of a pregnant woman (P.R.), 33 years old, hospitalized in the 39th week of gestation in order to complete the pregnancy by Caesarean section. Her previous pregnancy was also delivered by Caesarean section. 
Her family and personal history are accurate. The first pregnancy was in 2005. An emergency Caesarean section was performed due to non-reassuring fetal heart tracing. She gave birth to a female child (body weight/BW 3,080 g, body length/BL $48 \mathrm{~cm}$ ). One year after childbirth she started taking oral contraceptives and took them for three years. The second pregnancy was in line with expectations and there were no signs of fetal or maternal health issues. At admission (in July 2010) the patient had no fever, the blood pressure was $125 / 75 \mathrm{mmHg}$. Biochemical parameters were normal. Obstetric and ultrasound results corresponded to the age of pregnancy. The day after admission a Caesarean section was performed. A live, female child was born (BW 3,320g, BL 48 cm, Apgar score 10/10).

During exploration of the abdominal cavity after delivery the surface of uterus and the surface of both fallopian tubes were discovered to be covered by many nodules of various sizes - from a few millimeters to about $2 \mathrm{~cm}$ in diameter (see Figure 1). Many nodules, mostly small, were located on the parietal peritoneum of the anterior abdominal wall and the lateral wall of the pelvis. Both ovaries were clinically normal. Nodules were not present on the surface of the bladder nor liver. Due to the suspected peritoneal carcinomatosis, an ex tempore biopsy was performed. The changes that were found, were benign. Tissue samples were taken for performing permanent pathohistologic analysis. The postoperative recovery was in accordance with expectations. The patient was discharged on the seventh day after surgery as a healthy puerpera. The first ultrasound examination was performed three months after childbirth and showed a smooth surface of uterus without presence of any nodules. The patient was examined by ultrasound three more times and no nodules were seen on uterus or elsewhere.

Figure 1. Intraoperative view of the uterus with disseminated peritoneal leiomyomatic nodules

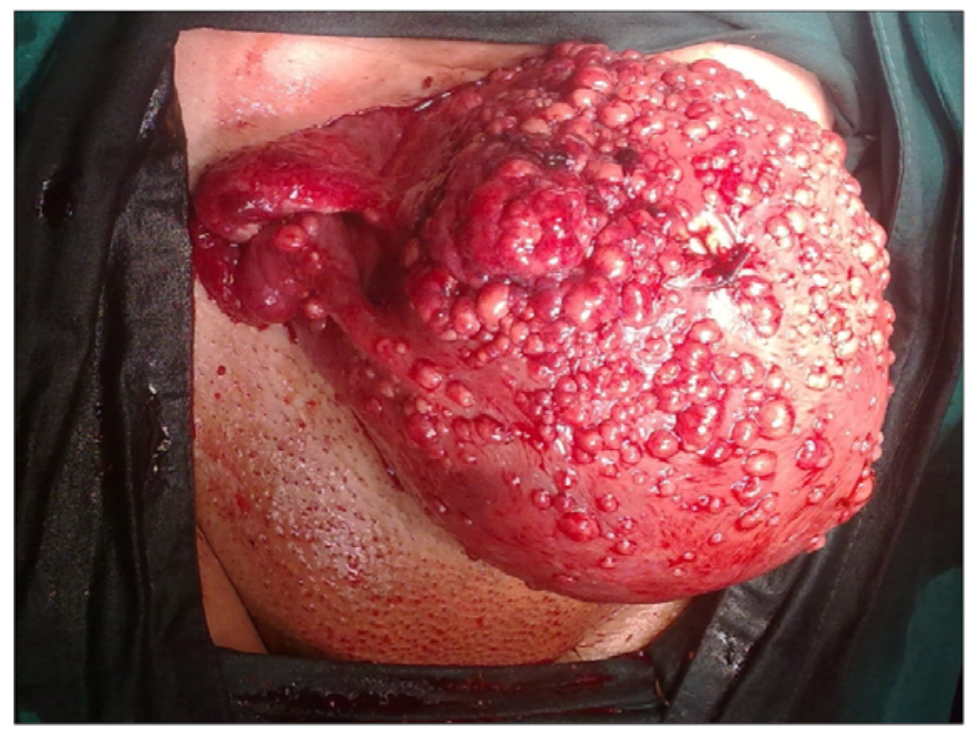

\subsection{The findings of the pathologist}

The analyzed materials were: (1) nodule from the uterine surface and (2) nodule from the peritoneal surface.

\subsection{Histopathological description}

Intraoperative histopathological finding speaks in favor of mesenchymal tumor. Histologically, both analyzed samples are made up of bundles of smooth muscle cells. They showed mild focal polymorphisam, no mitosis nor necrosis. Scraps of connective tissue are partially visible. Histochemical staining by PAS and Mallory Alc is in accordance with the mentioned description. Findings in both materials correspond to fragments of smooth muscle-leiomyoma, with no signs of malignancy in the examined sections (see Figures 2-5). 
Figure 2. Histopathological presentation of disseminated peritoneal leiomyomatsis, HE staining, magnification of $40 \times$.

Figure 3. Histopathological presentation of disseminated peritoneal leiomyomatsis, HE staining, magnification of $200 \times$.

Figure 4. Histopathological presentation of disseminated peritoneal leiomyomatsis, Mallory staining, magnification of $40 \times$.
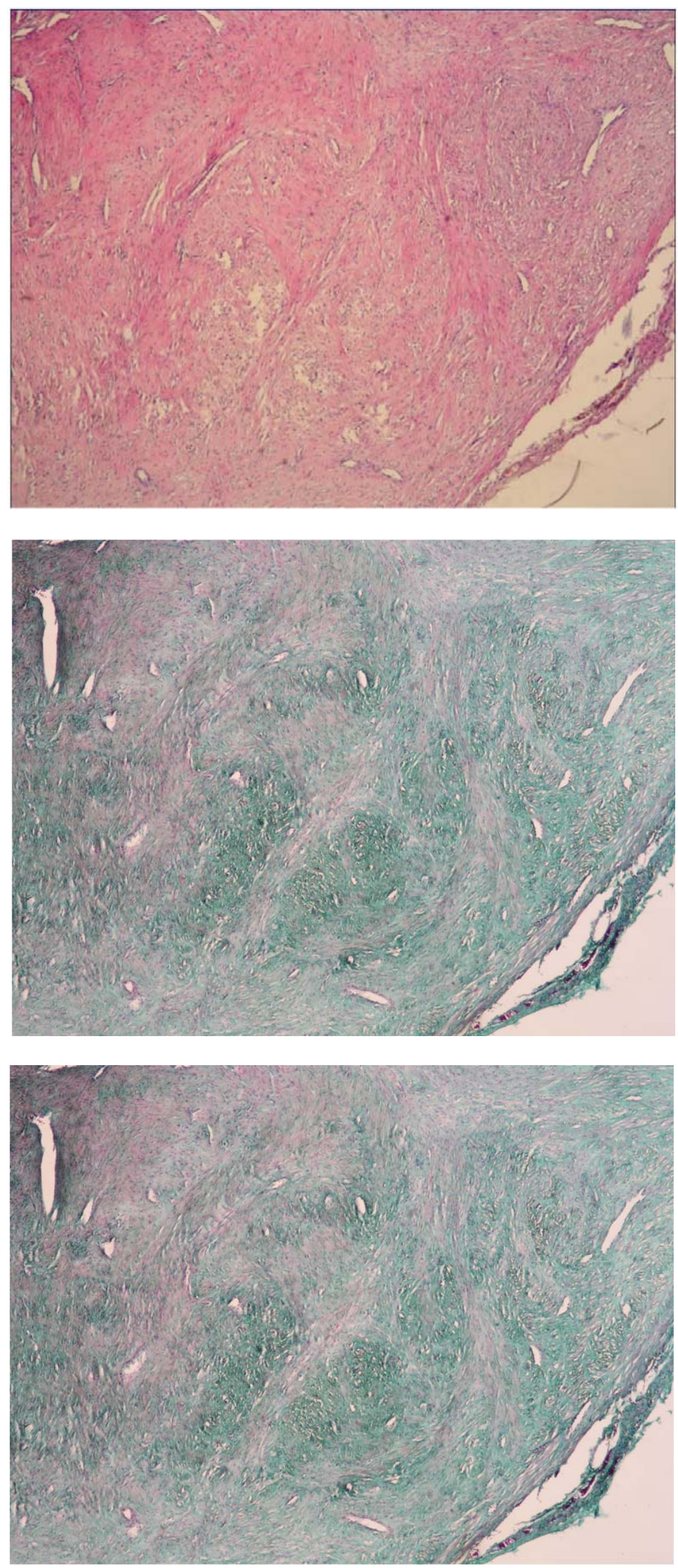
Figure 5. Histopathological presentation of disseminated peritoneal leiomyomatsis, Mallory staining, magnification of 200×.

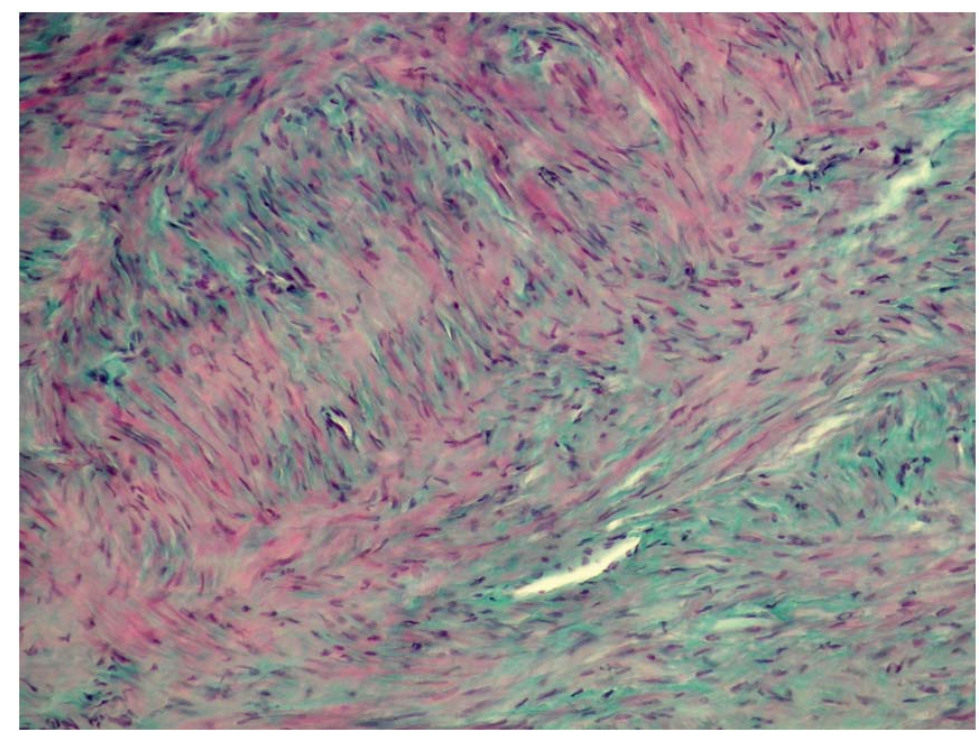

\section{Discussion}

Disseminated peritoneal leiomyomatosis is a rare, but well-documented clinical diagnosis. The disease is mainly asymptomatic, only in a few cases pain in abdomen and vaginal or rectal bleeding has been described ${ }^{[3]}$.

The diagnosis of DPL is set through a histopathological finding of smooth-muscle cells without atypia and necrosis. Possible differential diagnoses include: parasitic leiomyoma, intravenous leiomyomatosis, and primary or secondary peritoneal carcinomatosis ${ }^{[4]}$.

The etiology of the disorder is uncertain, but it seems that the DPL is a multifactorial disease with genetic and hormonal components (high levels of estrogen and progesterone). These components lead to metaplasia of mesenchymal peritoneal cells ${ }^{[5]}$.

The evidence that indicates that the disease is associated with hormonal disbalance are: (1) incidence of the disease only among women; (2) connection with pregnancy or intake of hormonal medicaments; (3) incidence of disease simultaneously with the existence of granulosa-cell tumor; (4) withdrawal of disease after castration (surgical or chemical) or termination of pregnancy; and (5) expression of estrogen and progesterone receptors in tumor cells, as well as experimentally induced disease by providing large amounts of estrogen or combined estrogen and progestagen in pigs ${ }^{[6-8]}$.

Metaplasia of subcelomic mesenchyma is responsible for the development of DPL and endometriosis. Peritoneum (parietal and visceral) and female internal genital organs evolve from celomic mesenchyma. Mesenchymal cells are pluripotent and can differentiate into endometriotic or smooth-muscle cells causing DPL ${ }^{[5,9,10]}$.

Endometriotic foci were found within leiomyomatic nodules in DPL in a few described cases. Endometriosis and the DPL together were found in several patients. DPL was also described in patients with granulosa-cell tumor or ovary teratoma ${ }^{[5]}$.

In patients with DPL who were followed throughout a longer period, the complete regression of the disease occurred. It is assumed that the regression occurs because of castration (surgical/chemical) or ending of pregnancy and thereby reducing level of hormones. In all patients in whom the DPL was related to pregnancy or taking oral contraceptives, the disease spontaneously regressed after delivery or cessation of oral contraceptive use. Although the disease regresses most often (spontaneously or with treatment), it can also persist for years. Malignant alteration is described in some cases ${ }^{[11]}$. 


\section{Conclusion}

In the described case we were impressed by the changes in the visceral and parietal peritoneum, which looked like peritoneal carcinomatosis. Fortunately it was a disseminated peritoneal leiomyomatosis.

DPL is a very rare disease which can be seen only by some gynecologists during their professional career. Although the disease spontaneously and completely regresses in the majority of cases after delivery or ending of use of contraceptives, we recommend regular monitoring of patients by bimanual and ultrasound examinations.

\section{References}

[1] Wilson JL, Peale AR. Multiple peritoneal leiomyomas associated with a granulosa-cell tumor of the ovary. Am J Obstet Gynecol. 1952; 64: 204-8.

[2] Williams LJ, Pavlick FJ. Leiomyomatosis peritonealis disseminata: two case reports and a review of the medical literature Cancer. 1980; 45: 1726-33. http://dx.doi.org/10.1002/1097-0142(19800401)45:7<1726::AID-CNCR2820450735>3.0.CO;2-B

[3] Atterman K, Fraser GM, Lea RH. Disseminated peritoneal leiomyomatosis. Virchows Arch (Pathol Anat). 1977; 374: 13-26.

[4] Lim OW, Zegal A, Ziel HK. Leiomyomatosis peritonealis disseminata associated with pregnancy. Obstet Gynaecol. 1980; 55: 122-5. PMid: 7352053.

[5] Parmley RH, Woodruff JD, Winn K. Histogenesis of leiomyomatosis peritonealis disseminata: ultrastructural study and histogenetic consideration. Am J Surg Pathol. 1980; 53: 451-6.

[6] Ceccaci I, Jacobs J, Powel A. Leiomyomatosis peritonelais disseminata: report of a case in a non-pregnant women. Am J Obstet Gynaecol. 1982; 144: 105-9.

[7] Kuo T, London SN, Dinh TV. Endometriosis occuring in leiomyomatosis peritonealis disseminata: ultrastructural study and histogenic considerations. Am J Surg Pathol. 1980; 4: 197-204. PMid: 7377465. http://dx.doi.org/10.1097/00000478-198004000-00012

[8] Nguyen GK. Disseminated leiomyomatosis peritonealis: report of a case in a postmenopausal woman. Can J Surg. 1993; 36: 46-8. PMid: 8443717.

[9] Due W, Peckartz H. Leiomyomatosis peritonealis disseminata: immunohistologic detection of estrogen and progesterone receptors in disseminated peritoneal leiomyomatosis. Int J Gynaecol Pathol. 1989; 8: 46-53. http://dx.doi.org/10.1097/00004347-198903000-00006

[10] Fujii S, Nakashima N, Okamura H, Takenaka A, Kanzaki H, Okuda Y, et al. Progesterone-induced smooth muscle-like cells in the subperitoneal nodules produced by estrogen. Experimental approach to leiomyomatosis peritonealis disseminata. Am J Obstet Gynecol. 1981; 139(2): 164-72. PMid: 7457531.

[11] Bekkers RL, Willemsen WN, Schijf CP, Massuger LF, Bulten J, Merkus JM. Leiomyomatosis peritonealis disseminata: does malignant transformation occur? A literature review. Gynecol Oncol. 1999; 75(1): 158-63. PMid: 10502446.

http://dx.doi.org/10.1006/gyno.1999.5490 